\title{
Cellular plasticity of trans- and dedifferentiation markers in human hepatoma cells in vitro and in vivo
}

\author{
SAMIR JABARI $^{1}$, MATTHIAS MEISSNITZER ${ }^{2 *}$, KARL QUINT $^{1}$, SUSANNE GAHR ${ }^{1}$, \\ TILL WISSNIOWSKI ${ }^{1}$, ECKHART G. HAHN ${ }^{1}$, DANIEL NEUREITER ${ }^{2 *}$ and MATTHIAS OCKER ${ }^{1}$ \\ ${ }^{1}$ Department of Medicine 1, University Hospital Erlangen, Erlangen, Germany; \\ ${ }^{2}$ Institute of Pathology, Salzburger Landeskliniken, Paracelsus Private Medical University, Salzburg, Austria
}

Received February 4, 2009; Accepted March 30, 2009

DOI: 10.3892/ijo_00000314

\begin{abstract}
Tumor cells have the capability to trans- and to dedifferentiate, for example by reactivating embryonic development genes and stem cell characteristics. The aim of our study was to show the differential expression of stem- and progenitor cell markers in human hepatocellular carcinoma cell lines (HCC). Different human HCC cell lines (HUH7, HUH7 5-15, HUH7 pcDNA3.1, Hep3B and HepG2) were cultured under standard conditions in vitro or implanted subcutaneously $\left(5 \times 10^{6}\right.$ cells) in male NMRI mice. Specimens were characterized by quantitative real-time PCR, Western blotting, methylation-specific PCR and immunohistochemistry for markers of differentiation (cytokeratins, vimentin), embryonic development or stem cells (PTC, PDX-1, SHH, Thy1, c-kit, CD34, ß-catenin, Ki-67). The investigated HCC cell lines showed different patterns of marker expression allowing to distinguish four distinct groups: the classical cholangiocellular type (Huh-7, Huh-7 pcDNA3.1, Hep3B) with expression of CK7/19, B-catenin and CD34; a dedifferentiated mesenchymal-proliferative type (Huh-7 5-15) characterized by CK19, Vimentin and Ki-67; a dedifferentiated embryonic-development type (Hep3B implanted in matrigel) with expression of CK19, B-catenin and PTC and a classical HCC type (HepG2) showing CK18/19 and B-catenin expression. HCC cell lines showed significantly different expression patterns of differentiation markers in a xenograft model. Furthermore, direct association of some markers was observed. The groups differ from each other in expression patterns, but also show that environmental factors play an important role in the behaviour of cells.
\end{abstract}

Correspondence to: Dr Matthias Ocker, Department of Medicine 1, University Hospital Erlangen, Ulmenweg 18, D-91054 Erlangen, Germany

E-mail: matthias.ocker@uk-erlangen.de

*Contributed equally

Key words: hepatocellular carcinoma, embryonic marker genes, trans- and dedifferentiation

\section{Introduction}

The liver is an epithelial organ which consists mainly of two distinct differentiated cell types, hepatocytes and bile-duct cells $(1,2)$. Bile duct cells are limited to the periportal region of the liver, while hepatocytes are present throughout the whole liver. Although the phenotype of these two cell types is different, they are thought to derive from one single stem cell, the oval cell, which is located at the periportal region (3-5). Oval cells are conceived to be the progenitor cells of both cell types, streaming out from the periportal region to repopulate, for example, injured liver tissue. It is still unclear which role this stem cell plays in postnatal human liver and whether it gives rise to both cell types or not (6-13). Other data show that division of hepatocytes may be the leading mechanism of hepatocellular renewal $(11,14)$, while a third theory indicates that migrating bone marrow cells give rise to progenitor and terminated liver cell types (3-5).

Trans- and dedifferentiation programs as well as putative tumor stem cells have been identified in different human gastrointestinal cancers (15) and we have shown previously that pancreatic cancer cell lines show a differential expression of embryonic regulatory genes dependent on their environment $(16,17)$.

Although some hepatocellular carcinoma cells (HCC) morphologically resemble oval cells as well as other hepatocytes, it is still uncertain whether hepatoma cells reacquire embryonic pathways and therefore resemble stem cells or are really of stem cell origin $(2,5)$. Different markers have been found to distinguish between progenitor cells (CK19, THY1) and differentiated (CK8, CK18) hepatocytes and we therefore investigated the epigenetic regulation of embryonic differentiation genes (PTC, SHH, THY1, c-kit and PDX-1) by methylation-specific PCR (MSP), quantitative real-time RT-PCR, immunoblotting and immunohistochemistry from typical HCC cell lines and xenografts established from these cells.

\section{Materials and methods}

Cell culture. HepG2 cells were cultured in RPMI-1640 medium containing $10 \%(\mathrm{v} / \mathrm{v})$ fetal bovine serum, penicillin $\left(10^{6} \mathrm{U} / \mathrm{l}\right)$, streptomycin $(10 \mathrm{mg} / \mathrm{l})$ and $0.5 \%(\mathrm{v} / \mathrm{v})$ gentamycin. Hep3B and HUH7 hepatoma cells were cultured in Dulbecco's 
minimal essential medium (DMEM) with the same supplements. HUH7pcDNA3.1 and the HCV replicon cell line HUH7 5-15, which stably expresses the non-structural hepatitis C virus genes NS3 through NS5B, were a gift of R. Bartenschlager (Department of Virology, University Heidelberg, Germany) $(18,19)$ and were cultured in DMEM medium as described with $2 \%(\mathrm{v} / \mathrm{v}) \mathrm{G} 418$. HUH7 5-15 was selected to investigate the influence of viral genes on cellular differentiation in HCC tumorigenesis and to compare the results with the parental cell line $\mathrm{HUH} 7$ and the transfection control HUH7pcDNA3.1. All cells were cultured at $37^{\circ} \mathrm{C}$ in a humified atmosphere containing $5 \% \mathrm{CO}_{2}$. All cell culture media and supplements were obtained from Biochrom, Berlin, Germany.

Xenograft model. HCC cell lines were harvested and resuspended in sterile physiologic $\mathrm{NaCl}_{2}$ solution. Cells $\left(5 \times 10^{6}\right)$ were injected subcutaneously into the flank of 4- to 6-week old male NMRI mice (Harlan Winkelmann GmbH, Borchen, Germany). For each cell line, three animals were used. Animals were kept in a light- and temperature-controlled environment and provided with food and water ad libitum. After 25 to 60 days, animals were sacrificed by cervical dislocation and specimens of tumors were either fixed in $10 \%$ phosphatebuffered formalin or snap-frozen in liquid nitrogen. Ethical approval was achieved before the beginning of the experiments.

RNA isolation and reverse transcription. Total cellular RNA was extracted by the use of peqGOLD RNAPure (PEQLAB Biotechnologie $\mathrm{GmbH}$, Erlangen, Germany), as described in the manual. RNA was pooled from all cell lines and animals of one group. First-strand cDNA was synthesized using Superscript II RNAse H-Reverse Transcriptase (Life Technologies, Karlsruhe, Germany). RNA ( $1 \mu \mathrm{g})$ of elute was added to $2 \mu \mathrm{l}$ of Oligo Mix and then filled up with DEPC-water to a total volume of $12 \mu \mathrm{l}$. After annealing for $10 \mathrm{~min}$ at $70^{\circ} \mathrm{C}$ and immediate cooling on ice, $5 \mathrm{X}$ first-strand buffer (Life Technologies), $10 \mathrm{mM}$ DTT (Life Technologies), $0.5 \mu 1$ enzyme (100 U) and $0.5 \mathrm{mM}$ deoxynucleotide triphosphate (Carl Roth GmbH, Karlsruhe, Germany) were added to get a total reaction volume of $21 \mu 1$. The reaction was allowed to proceed for $50 \mathrm{~min}$ at $42^{\circ} \mathrm{C}, 30 \mathrm{~min}$ at $52^{\circ} \mathrm{C}, 25 \mathrm{~min}$ at $60^{\circ} \mathrm{C}$ followed by $15 \mathrm{~min}$ at $70^{\circ} \mathrm{C}$ to inactivate the enzyme. cDNA was stored at $-20^{\circ} \mathrm{C}$ until use.

Quantitative real-time RT-PCR. Primers were designed by use of Primer express software Version 2.0.0 (Perkin-Elmer Applied Biosystemy, Foster City, CA, USA) and FastPCR Version 4.0.27 (Ruslan Kalendar 'PCR Team', Helsinki, Finland). The sequences of species-specific primers are listed in Table I. Primers were obtained from MWG Biotech, Martinsried, Germany. The $20 \mu 1$ of total PCR volume consisted of $2 \mu \mathrm{l}$ cDNA, $2 \mu \mathrm{l}$ master mix SYBR-Green I (Applied Biosystems, Martinsried, Germany), $3.2 \mu 1 \mathrm{MgCl}_{2}$, $8.8 \mu \mathrm{l}$ water and $4 \mu \mathrm{l}$ primer in the following concentration: $800 \mathrm{nM}$ each for GAPDH and $400 \mathrm{nM}$ each for the residual genes. After denaturating and activation of the hotstart enzyme for $10 \mathrm{~min}$ at $95^{\circ} \mathrm{C}$, the PCR assays were carried out for 45 cycles, with denaturation at $95^{\circ} \mathrm{C}$ for $10 \mathrm{sec}$, annealing and extension at $72^{\circ} \mathrm{C}$ for $1 \mathrm{~min}$. To monitor amplification of possible contaminated DNA, distilled water served as a negative control. Fluorometric PCR was performed with the Roche Lightcycler system (Roche Applied Science, Mannheim, Germany). Threshold cycle was set when emission intensity of mesurable fluorescence calibrated to starting level became equal to 10 standard deviations of the baseline. The RT-PCR results were expressed as the ratio of molecules of target gene per 1000 molecules of the housekeeping gene (GAPDH). Melting curve analysis was performed after each PCR run. After denaturation at $95^{\circ} \mathrm{C}$ for $10 \mathrm{sec}$, a temperature ramp from 65 to $95^{\circ} \mathrm{C}$ in 20 min was run with simultaneous acquisition of fluorescence signals. Using negative first-deviation plots, we checked each sample for primer dimers and unspecific products due to mispriming.

Protein isolation and Western blotting. Proteins were isolated after centrifuging hepatoma cells at 1,000 rpm for $10 \mathrm{~min}$, discarding the liquid phase and adding $50 \mu 1$ of Jie's protein lysis buffer, consisting of $10 \mathrm{mM} \mathrm{NaCl}{ }_{2}, 0.5 \% \mathrm{NP}_{4} \mathrm{O}, 20 \mathrm{mM}$ Tris-HCl pH 7.4, 5 mM MgCl $2,10 \mu \mathrm{g} / \mathrm{ml}$ Prot-I, 1 mM PMSF. After 30 min cooling on ice with intermediate vortexing, the suspension was divided into two portions, ready to use and stored at $-80^{\circ} \mathrm{C}$.

Samples were subjected to electrophoresis on precast Novex Tris-Glycine gels (Invitrogen) and then blotted to nitrocellulose membranes. Membranes were blocked with $5 \%$ low fat milk at $4^{\circ} \mathrm{C}$ overnight and then incubated with primary antibodies as described in Table II. Signals were retrieved using enhanced chemiluminescence on Kodak X-Omat LS film. Membranes were glycin shocked and re-probed with an antibody against $\beta$-actin as an internal standard. Densitometry was performed with GelScan 5 software (BioSciTec, Frankfurt, Germany) by normalizing density values to $\beta$-actin values of each sample.

DNA isolation and methylation-specific PCR (MSP). Cellular DNA was extracted using the QIamp DNA mini kit (Qiagen, Hilden, Germany) for each cell line and from snap-frozen tumor samples according to the manufacturer's instructions.

Bisulphate modification of the DNA was accomplished by the use of the EZ Methylation-Gold kit (Zymo Research, Orange, USA) as described in the manual. DNA elements with methylated cytosins remain unmodified after bisulfite treatment while unmethylated cytosins will be completely converted into uracil nucleosides and further to thymine after PCR, thus giving different primer recognition sequences for MSP.

PCR-mix (2X) (12.5 $\mu$ l) (Fermentas, St. Leon-Rot, Germany) were added to $2 \mu 1$ of bisulfonated/unmodified DNA sample followed by $1 \mu \mathrm{l}$ of forward and reverse primers (400 nM each). Finally, $8.5 \mu 1$ of water was added. PCR reaction was run at a temperature of $94^{\circ} \mathrm{C}$ for $2 \mathrm{~min}$ followed by 35 cycles $\left(94^{\circ} \mathrm{C}\right.$ for $10 \mathrm{sec}, 60^{\circ} \mathrm{C}$ to $70^{\circ} \mathrm{C}$ according to annealing temperature of the primer for $20 \mathrm{sec}, 72^{\circ} \mathrm{C}$ for $20 \mathrm{sec}$ ) and terminated by $72^{\circ} \mathrm{C}$ for $4 \mathrm{~min}$ and immediate cooling down to $4^{\circ} \mathrm{C}$. Primer sequences and annealing temperatures are given in Table III.

PCR products were subjected to $2 \%(\mathrm{w} / \mathrm{v})$ agarose gel electrophoresis after staining with 6x Loading Dye Solution (Fermentas). GeneRuler 100 bp DNA Ladder Plus was used as a length standard (Fermentas GmbH, St. Leon Roth, Germany). 
Table I. Sequences of primers used for real-time PCR experiments.

\begin{tabular}{|c|c|c|c|}
\hline & NCBI reference sequence no. & Amplicon (bp) & Primer \\
\hline CK7 & X13320 & 75 & $\begin{array}{l}\text { Forward (exon 4): 5'-TGAATGATGAGATCAACTTCCTCAG-3' } \\
\text { Reverse (exon 5): 3'-TGTCGGAGATCTGGGACTGC-5' }\end{array}$ \\
\hline CK8 & BC000654 & 101 & $\begin{array}{l}\text { Forward (exon 7): 5'-CTGGGATGCAGAACATGAGTATTC-3' } \\
\text { Reverse (exon 8): 3'-GTAGCTGAGGCCGGCTTGT-5' }\end{array}$ \\
\hline CK18 & ВC000180 & 86 & $\begin{array}{l}\text { Forward (exon 5): 5'-GAGACGTACAGTCCAGTCCTTGG-3' } \\
\text { Reverse (exon 6): 3'-CCACCTCCCTCAGGCTGTT-5' }\end{array}$ \\
\hline CK19 & NM_002276 & 1377 & $\begin{array}{l}\text { Forward (exon 1): 5'-CGGGCATAAAAGGCGCCAGGT-3' } \\
\text { Reverse (exon 6): 3'-GAGACCCCGAAGACGACAGGAAAC-5' }\end{array}$ \\
\hline CK20 & $\mathrm{X} 73502$ & 105 & $\begin{array}{l}\text { Forward (exon 5): 3'-TCCCAGAGCCTTGAGATAGAACTC-5' } \\
\text { Reverse (exon 6): 5'-GTTGGCTAACTGGCTGCTGTAAC-3' }\end{array}$ \\
\hline Vim & 003380 & 208 & $\begin{array}{l}\text { Forward primer (exon 5): 5'-TGAGGCTGCCAACCGGAAACA-3' } \\
\text { Reverse primer (exon 6): 5'-TTGGCCTGCAGGATGAG-3' }\end{array}$ \\
\hline PTC & NM_000264 & 139 & $\begin{array}{l}\text { Forward (exon 3): 5'-CCAATCTTCTGGCGAGTATAATTTAAT-3 } \\
\text { Reverse (exon 2): 3'-TGGTTGTGGGCCTCCTCAT-5' }\end{array}$ \\
\hline SHH & X13320 & 117 & $\begin{array}{l}\text { Forward (exon 3): 5'-GGAAGCAGCCTCCCGATT-3' } \\
\text { Reverse (exon 2): 3'-CGAGTCCAAGGCACATATCCA-5' }\end{array}$ \\
\hline PDX-1 & NM_008814 & 64 & $\begin{array}{l}\text { Forward (exon 1): 3'-TTCCCATGGATGAAGTCTACCAA-5' } \\
\text { Reverse (exon 1+2): 5'-CGTAGGCGCCGCCTG-3' }\end{array}$ \\
\hline THY-1 & NM_006288 & 235 & $\begin{array}{l}\text { Forward (exon 4): 5'-GACCCGTGAGACAAAGAAGC-3' } \\
\text { Reverse (exon 4): 3'-TTGACCAGTTCACACTCCCG-5' }\end{array}$ \\
\hline C-KIT & NM_000222 & 3998 & $\begin{array}{l}\text { Forward (exon 1): 5'-TCGCTGCACTTGGGCGAGAGCT-3' } \\
\text { Reverse (exon 21): 5'-TTTTCCCACTCCTGTGGGAGC-3' }\end{array}$ \\
\hline GAPDH & NM_002046 & 226 & $\begin{array}{l}\text { Forward (exon 4): 5'-GAAGGTGAAGGTCGGAGTC-3' } \\
\text { Reverse (exon 5): 3'-GAAGATGGTGATGGGATTTC-5' }\end{array}$ \\
\hline
\end{tabular}

Immunohistochemistry. Immunohistochemical staining procedures were applied, as described previously $(16,17)$. In short: $5-\mu \mathrm{m}$ sections were deparaffinized using graded alcohols. After antigen retrieval with microwave (MW) (10 mmol/l citrate buffer, $\mathrm{pH} 6.0 ; 8 \mathrm{~min}$ at $560 \mathrm{~W}$ and $8 \mathrm{~min}$ at $800 \mathrm{~W}$ ) or trypsin, the sections were incubated overnight using specific antibodies (Table II). Next, depending on the primary antibody, biotinylated rabbit anti-goat or goat antirabbit (Dako, Denmark) antibodies were applied on the sections. Detection was done using the Dako streptavidinbiotin-complex and alkaline phosphatase system, following the user's manual (Dako). Development was done using DAB (Roche Molecular Biochemicals, Mannheim, Germany). Nuclei were counterstained with hematoxylin.

Hematoxylin-eosin staining was used to evaluate basic histomorphology of the specimens. The epithelial mucopolysaccharides were detected by the PAS reaction. The stained sections were independently analyzed (by DN and MM). Representative images were taken from 4 high power fields (x400 magnification) in each following scheme: negative (-), weak $(+)$, moderate $(++)$, strong $(+++)$, differing focal expression being indicated in round brackets. Additionally, the percentage of positive cells per high power field was determinated using ImageAccess Enterprise 5 software (Imagic Bildverarbeitung, Glattbrugg, Switzerland). For further statistical analysis the calculated product of intensity and extensity was used ranging from 0 (negative) to a maximum of 300 (3 staining intensity and $100 \%$ positive cells) section.

Statistics. Statistical analysis was performed with SPSS 14.0 using analysis of variances (ANOVA) in order to compare the different groups of xenografts. LSD and Tukey-HSD methods were applied as post hoc tests. Correlation coefficients were calculated according to Pearson. For detecting homogeneous clusters of cases based on measured characteristics hierarchical cluster analysis (average linkage method) were carried out. Additionally, factor analysis with varimax method were used to condense the relevant variable in the clusters. All tests were two tailed. A P-value of $<0.05$ was considered statistically significant.

\section{Results}

Analysis of mRNA expression. Expression of cytokeratin (CK) $7,8,18,19$ and 20 as well as of vimentin (vim) was analysed 
Table II. Primary antibodies and antigen retrieval methods used for Western blotting or immunohistochemical analysis.

\begin{tabular}{|c|c|c|c|c|}
\hline Antigen specificity & Type & Dilution & Antigen retrival & Vendor \\
\hline CK7 & Mouse monoclonal & $1: 200$ & TRS & NovaCastra \\
\hline CK8/CK18 & Mouse monoclonal & $1: 400$ & TRS & NovaCastra \\
\hline CK19 & Mouse monoclonal & $1: 100$ & TRS & Dako \\
\hline CK20 & Mouse monoclonal & $1: 50$ & TRS & NovaCastra \\
\hline Vimentin & $\begin{array}{c}\text { Mouse monoclonal }^{\mathrm{a}} \\
\text { Goat polyclonal }\end{array}$ & $1: 2000$ & TRS & $\begin{array}{c}\text { Dako }^{\mathrm{a}} \\
\text { SantaCruz }\end{array}$ \\
\hline ß-catenin & Mouse monoclonal & $1: 200$ & TRS & Dako \\
\hline $\mathrm{Ki}-67$ & Mouse monoclonal & $1: 500$ & TRS & Dako \\
\hline pdx-1 & Mouse monoclonal polyclonal & $\begin{array}{r}1: 20^{\mathrm{a}} \\
1: 5000\end{array}$ & TRS & $\begin{array}{c}\mathrm{R} \& \mathrm{D}^{\mathrm{a}} \\
\text { Chemicon }\end{array}$ \\
\hline shh & Goat polyclonal & $\begin{array}{c}1: 100^{\mathrm{a}} \\
1: 200\end{array}$ & MW, TRS & SantaCruz \\
\hline ptc & Goat polyclonal & $\begin{array}{c}1: 50^{\mathrm{a}} \\
1: 200\end{array}$ & MW, TRS & SantaCruz \\
\hline CD34 & Mouse monoclonal & $1: 200$ & TRS & Dako \\
\hline c-kit & Mouse monoclonal & $1: 200$ & TRS & NovaCastra \\
\hline Thy-1 & Goat polyclonal & $1: 50$ & MW, TRS & SantaCruz \\
\hline B-actin & Mouse monoclonal & $1: 5000$ & & Sigma \\
\hline
\end{tabular}

MW, microwave (10 mmol/l citrate buffer, $\mathrm{pH} \mathrm{6.0;10} \mathrm{min} \mathrm{at} 800 \mathrm{~W}$ and $10 \mathrm{~min}$ at $560 \mathrm{~W}$ ); TRS, target retrieval solution (pH 9.0; Dako, Germany) used instead of citrate buffer. ${ }^{\text {a }}$ mmunohistochemistry.

to determine the differentiation status of HCC xenografts (Fig. 1A). Expression of CK7 was low in Hep3B, Huh-7 and Huh-7 pcDNA3.1 with a slight increase in Huh-7 5-15. HepG2 xenografts showed a 5-fold higher expression of CK7. In contrast, CK8 was highly expressed in Hep3B and Huh-7 but was reduced to low levels in the other cell lines. CK18 was evenly expressed in all investigated cell lines, while only low levels of CK19 were detected. Expression of CK20 was high in HepG2 and low to moderate in the other cell lines. All cell lines showed also a low to moderate expression of vimentin.

In vitro, expression of CK7 was low to moderate in all cell lines except Huh-7 pcDNA3.1 which showed a 40-fold higher expression (data not shown). CK8 was expressed at very low levels, while CK18 expression was homogeneous and moderate in all investigated cell lines. Expression of CK19 and CK20 was moderate in all cell lines. Except for Huh-7 5-15 cells, where a 2-fold induction was observed, the mesenchymal maker vimentin was expressed at low levels only in the other cell lines.

We then investigated the expression of embryonic differentiation and stem cell marker genes in the xenograft model (Fig. 1B). Hep3B and Huh-7 showed a similar pattern of high expression of $\mathrm{SHH}$ and c-kit, intermediate expression of PDX-1 and absence or low expression of PTC and Thy-1. HepG2 cells, in contrast, did not express SHH and showed only low levels of Thy-1 and c-kit, while PDX-1 was highly expressed here. In Huh-7 5-15 cells, only Thy-1 and c-kit were detectable by quantitative real-time RT-PCR. Interestingly, these markers were expressed at very low levels in the control cell line Huh-7 pcDNA3.1. This cell line also expressed SHH, PTC and PDX-1 at moderate levels.

The analysis of these markers under in vitro conditions showed a differential pattern (Fig. 1C). SHH was homogeneously expressed in all cell lines except HepG2, where a marked suppression of this gene was observed. PTC was not detectable under in vitro conditions, while PDX-1 showed a constant expression in all cell lines. Thy-1 was expressed at moderate to high levels, while c-kit was highly expressed in Hep3B, Huh-7 and Huh-7 pcDNA3.1 but was not detectable in HepG2 and was strongly suppressed in Huh-7 5-15.

Comparison of in vitro and in vivo mRNA analysis. The comparison of the two experimental setups revealed differences in the expression of the investigated markers. While no changes were observed for CK7, except for a strong upregulation in Huh-7 pcDNA3.1 xenografts, CK8 was induced in Hep3B and Huh-7 samples from nude mice. The hepatocellular marker CK18 was unaffected by the change of environment, but CK19 was lost in all investigated xenografts compared to cell culture conditions. The glandular/intestinal marker CK20 was downregulated in Huh-7 and its derivatives in vivo while it was unchanged in Hep3B and even induced in HepG2. The 
Table III. Sequences of primers used for methylation-specific PCR analysis.

\begin{tabular}{|c|c|c|c|}
\hline & NCBI reference sequence no. & Amplicon (bp) & Primer \\
\hline C-KIT & NT_022853 & 160 & $\begin{array}{l}\text { Forward: 5'-AGCAAGAGTTAACGATTCCGGAG-3' } \\
\text { Reverse: 3'-CCAGAAAGGTGTAAGTGCCTCCT-5' }\end{array}$ \\
\hline C-KIT MSP & NT_022853 & 164 & $\begin{array}{l}\text { Forward: 5'-GTTTGTAGGTTTTTCGTCGC-3' } \\
\text { Reverse: 5'-CGCAACCTTCGATTAATCTC-3' }\end{array}$ \\
\hline PDX-1 & NT_024524 & 100 & $\begin{array}{l}\text { Forward: 5'-GGGTTTTTTTTGGAGGGAGTT-3' } \\
\text { Reverse: 5'-CTTTCCACACTAAACTTTAAT-3' }\end{array}$ \\
\hline PDX-1 MSP & NT_024524100 & 100 & $\begin{array}{l}\text { Forward: 5'-GTTTTTTTCGGAGGGAGTC-3' } \\
\text { Reverse: 5'-TTTCCACGCGTAAACTTTAA-3' }\end{array}$ \\
\hline PTC & NT_008470 & 110 & $\begin{array}{l}\text { Forward: 5'-AGTAGTGGTTGGTTTGTTAATT-3' } \\
\text { Reverse: 3'-CACTACTACCACTACTACAAAC-5' }\end{array}$ \\
\hline PTC MSP & NT_008470 & 110 & $\begin{array}{l}\text { Forward: 5'-TAGCGGTTGGTTTGTTAATC-3' } \\
\text { Reverse: 5'-CGCTACTACCGCTACTACGA-3' }\end{array}$ \\
\hline SHH & NC_000007 & 117 & $\begin{array}{l}\text { Forward: 5'-ACCGAGGGCTGGGACGAAGATGGC-3' } \\
\text { Reverse: 5'-GCGAGCCAGCATGCCGTACTTGCTG-3' }\end{array}$ \\
\hline SHH MSP & NC_000007 & 120 & $\begin{array}{l}\text { Forward: 5'-TAGTTAGCGAGGGAGAGAGC-3' } \\
\text { Reverse: 3'-GAACTATCCCCGTACGAATC-5' }\end{array}$ \\
\hline THY-1 & NC_000011 & 120 & $\begin{array}{l}\text { Forward: 5'-TTATTTTTATATTAATGTGGGATTGT-3' } \\
\text { Reverse: 5'-TCCAATTACTACACCCAACTCAAA-3' }\end{array}$ \\
\hline THY-1 MSP & NC_000011 & 124 & $\begin{array}{l}\text { Forward: 5'-TATTTTTATATTAATGCGGGATCGT-3' } \\
\text { Reverse: 5'-CGATTACTACACCCAACTCGAA-3' }\end{array}$ \\
\hline
\end{tabular}

MSP, methylation-specific primer.

expression of the mesenchymal marker vimentin decreased in all xenograft specimens except for Huh-7 5-15 samples, where a moderate expression was established.

The in vitro expression pattern of $\mathrm{SHH}$ was also reflected in vivo, except for Huh-7 5-15 where a strong induction was observed. PTC was not detectable under cell culture conditions and only Huh-7 pcDNA3.1 xenografts showed moderate levels of this receptor. PDX-1, Thy-1 and c-kit tended to be downregulated in vivo, except for an increased expression of PDX-1 in HepG2 and Huh-7 pcDNA3.1 xenograft samples and a slight increase of c-kit in HepG2.

These findings indicate a differential expression of differentiation markers and genes regulating embryonic development dependent on the tumor cell environment.

Western blot analysis in vitro/vivo (Fig. 2). On the protein level, SHH was expressed in all cell lines in vitro and in vivo, with a slight decrease in Huh-7 xenografts, while its expression was increased in Huh-7 5-15 specimens. Thy-1 was expressed in all samples but was downregulated in the xenografts compared to cell culture material, which parallels the mRNA results described above. No expression was observed in Hep3B xenografts. PTC also showed a constant expression in all investigated samples with an increase in signal intensity in HepG2 xenografts and decreased expression in Huh-7 pcDNA3.1 xenografts. Corroborating the mRNA findings, no expression of the mesenchymal marker vimentin was observed, while cognate bands were detectable in vitro. Interestingly, PDX-1 was not detectable from HepG2 cell culture samples (although high mRNA levels were observed). All other cell lines, except Huh-7 pcDNA3.1 in vivo, expressed PDX-1 under both conditions.

Methylation-specific PCR analysis in vitro and in vivo (Fig. 3 and Table IV). MSP analysis revealed a methylated DNA status of Thy-1 in all cell lines and under both investigated conditions, while all other gene loci were not methylated in vitro or in vivo. Only PDX-1 showed a methylation signal in HepG2 in vitro, which was lost in xenograft specimens.

Expression pattern of markers in HCC-xenografts (Fig. 4 and Table $V$ ). i) The expression of intermediate filaments (CK7, CK8/18, CK19, CK20 and vimentin) was significantly differential in all xenografts (ANOVA test, $\mathrm{p}<0.001$ ). Expression of CK8/18 was lowest in Huh-7 derived cell lines whereas highest expression was found in native Hep3B or Hep3B implanted to nude mice with matrigel (Hep3B-MG) and especially in HepG2 xenografts. In contrast, the expression of CK7 was mainly found in Huh-7 5-15. This was associated with high expression of vimentin. Interestingly, CK19 was expressed in Hep3B as well as in HepG2 xenografts. CK20 expression levels were low in all investigated HCC xenografts. 
Table IV. Methylation-specific PCR analysis.

\begin{tabular}{|c|c|c|c|c|c|c|c|c|c|c|}
\hline & \multicolumn{2}{|c|}{ Hep3B } & \multicolumn{2}{|c|}{ HepG2 } & \multicolumn{2}{|c|}{ Huh-7 } & \multicolumn{2}{|c|}{ Huh-7 pcDNA3.1 } & \multicolumn{2}{|c|}{ Huh-7 5-15 } \\
\hline & In vivo & In vitro & In vivo & In vitro & In vivo & In vitro & In vivo & In vitro & In vivo & In vitro \\
\hline SHH & - & - & - & - & - & - & - & - & - & - \\
\hline Thy-1 & + & + & + & + & + & + & + & + & + & + \\
\hline c-kit & - & - & - & - & - & - & - & - & - & - \\
\hline PDX-1 & - & - & - & + & - & - & - & - & - & - \\
\hline PTC & - & - & - & - & - & - & - & - & - & - \\
\hline
\end{tabular}

Results of MSP analysis from cell culture and xenograft specimens. +, methylation and -, no methylation.

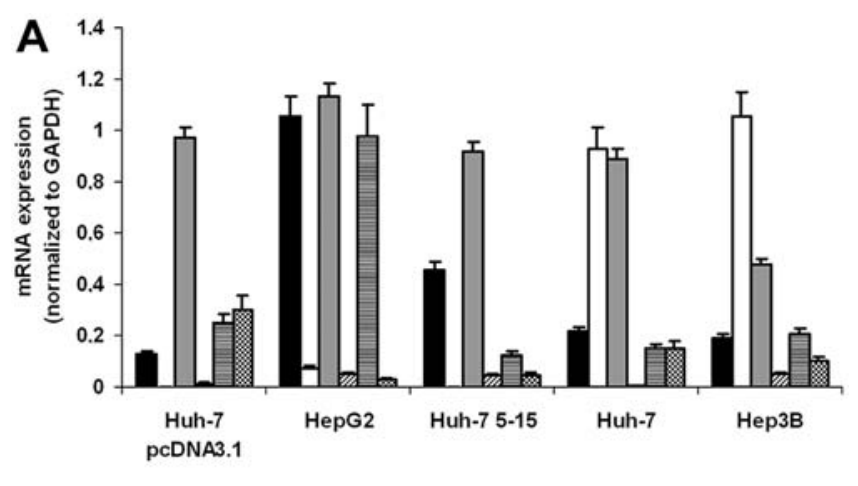

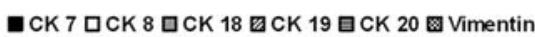
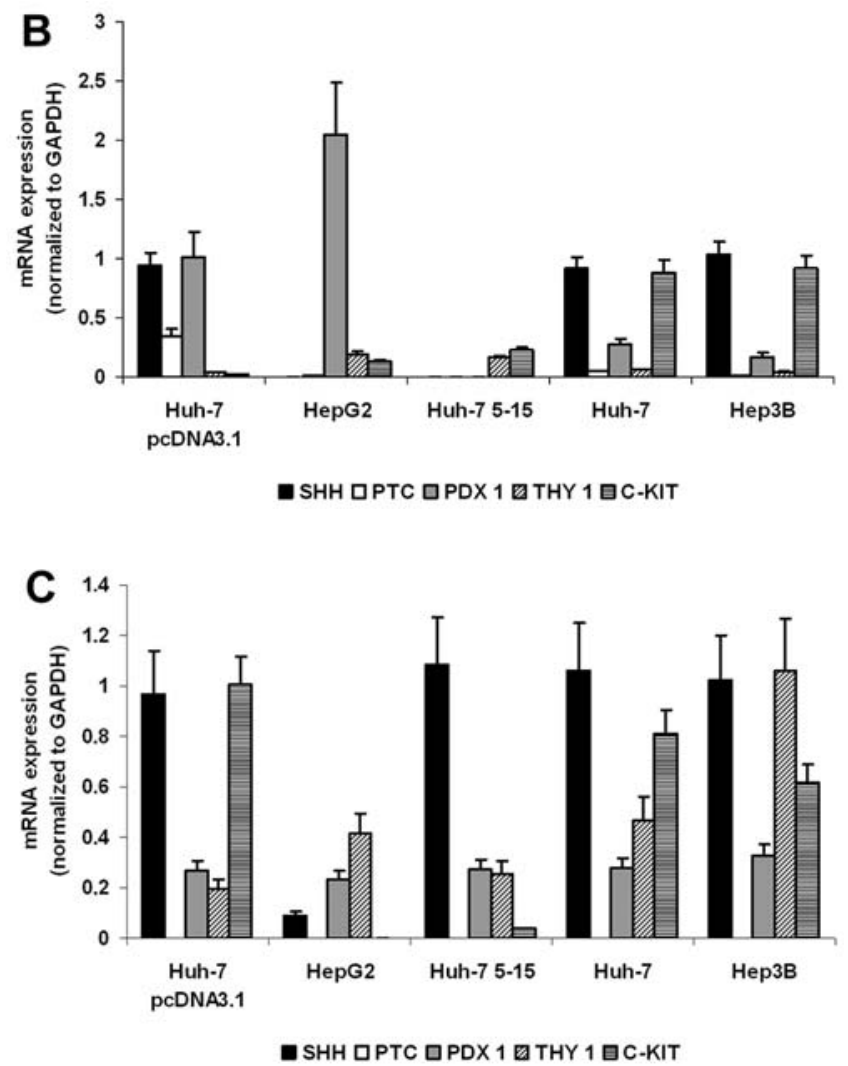

Figure 1. Quantitative real-time RT-PCR analysis of markers associated with differentiation and embryonic development in HCC cell lines and xenografts. mRNA levels were normalized to GAPDH expression. Analysis of differentiation markers (A) and embryonic development genes (B) from xenograft specimens and cell culture samples $(C)$. Shown are mean \pm SEM of three independent specimens.

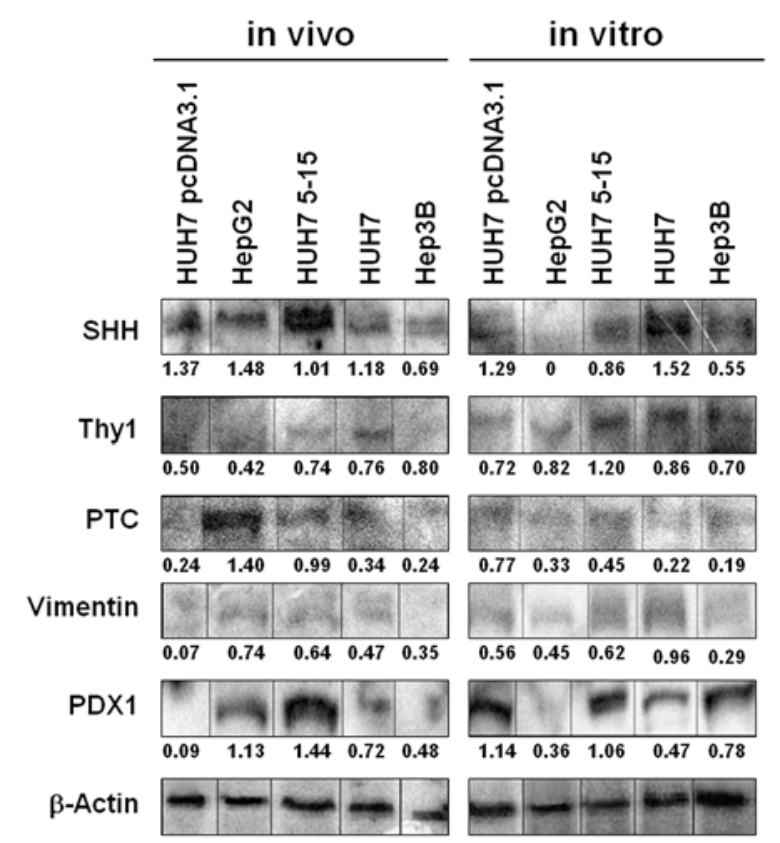

Figure 2. Representative Western blotting results comparing the expression of Sonic hedgehog (SHH), Thy-1, Patched (PTC), vimentin (VIM) and the pancreatic duodenal homeobox gene 1 (PDX-1) from HCC xenograft samples (left) and under standard cell culture conditions (right). $\beta$-actin bands were used to show equal loading of lanes. Numbers depict densitometric values normalized to $\beta$-actin values of each sample.

ii) Throughout all HCC xenografts, analysis of progenitor factors (c-kit, CD34, Thy-1) showed comparatively low expression levels. Peak expression levels of CD34 were observed in HepG2, THY-1 expression was highest in Hep3B-MG xenografts (ANOVA test, $\mathrm{p}<0.001$ ). iii) Finally, analysis of embryonic/developmental markers showed heterogeneous expression levels. Membranous $\beta$-catenin expression was mainly found in Huh-7, Hep3B and Hep3B$\mathrm{MG}$, whereas cytoplasmatic $\beta$-catenin was especially high in HepG2 cells. In addition, PDX1 was at highest levels in HepG2 xenografts (ANOVA test, $\mathrm{p}<0.001$ ). Expression of SHH was low in all xenografts, whereas expression of PTC was heterogeneous and peak PTC expression levels were found in Huh-7 pcDNA3.1 and Hep3B-MG (ANOVA test, $\mathrm{p}<0.001)$.

Correlation analysis of $m R N A$ and protein expression in vitro and in vivo. Comparing mRNA and protein expression of the 
in vivo

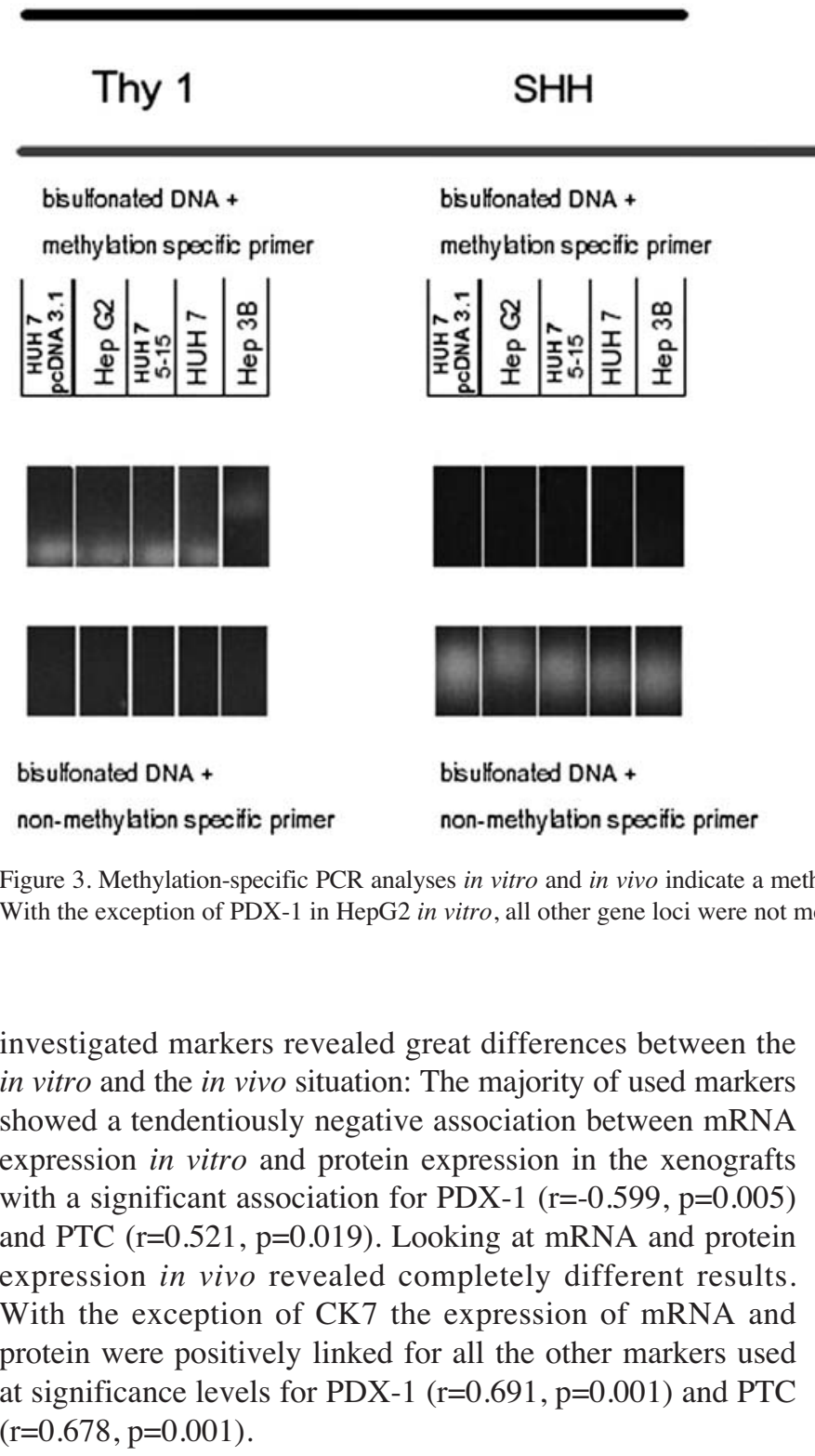

Correlation analysis of markers in HCC-xenografts (Table VI). Correlation analysis showed heterogeneous, significantly positive and negative associations: The ductal marker CK7 was positively correlated with the glandular/intestinal marker CK20. Interestingly, the hepatocellular marker CK8/18 was positively associated with the known ductal marker CK19 and the progenitor marker Thy- 1 but negatively linked to the mesenchymal marker vimentin. CK19, on the other hand, showed a significantly positive correlation with embryonic/ developmental markers such as cytosplamatic $\beta$-catenin and PDX-1 as well as a negative association with PTC. Finally, the mesenchymal marker vimentin was negatively associated with the progenitor markers CD34 and cytoplasmatic Bcatenin.

Looking at the progenitor marker CD34, a positive correlation to the embryonic/developmental markers PDX-1 and cytoplasmatic $\beta$-catenin as well as vimentin was observed. Thy- 1 showed a significantly positive association with CK8/18 and membranous B-catenin. No significant association between c-kit and any other investigated marker was found.

\section{in vitro}

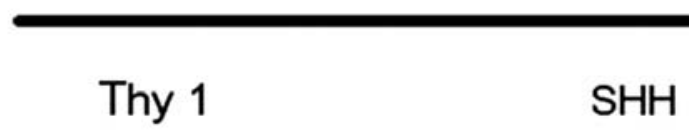

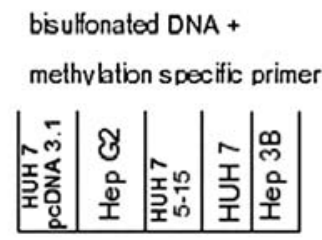
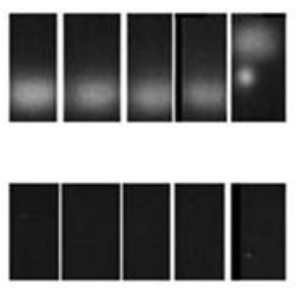

bisulfonated DNA +

non-methylation specific primer
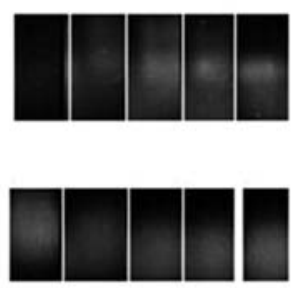

bisulfonated DNA +

non-methylation-specific primer methvlation specific primer

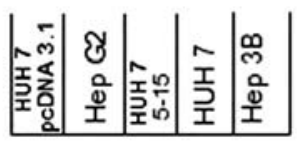

ated DNA status of Thy-1 in all cell lines under both experimental conditions. 
Table V. Expression levels inside different HCC xenografts.

\begin{tabular}{|c|c|c|c|c|c|c|}
\hline & \multicolumn{6}{|c|}{$\begin{array}{l}\text { Score (mean } \pm \text { standard deviation of mean) } \\
\text { intensity (mean)/extensity levels (mean) }{ }^{\mathrm{a}}\end{array}$} \\
\hline & HUH7 & HUH7 PC & HUH7 5-15 & Heb3b & Heb3b MG & HepG2 \\
\hline $\mathrm{Ki} 67^{\mathrm{b}}$ & $26.2 \pm 2.6$ & $40.0 \pm 2.1$ & $60.0 \pm 2.1$ & $22.7 \pm 1.1$ & $52.2 \pm 2.6$ & $49.7 \pm 2.3$ \\
\hline \multicolumn{7}{|c|}{ Intermediate filaments } \\
\hline \multirow[t]{2}{*}{ CK7 } & $1.9 \pm 0.9$ & $0.06 \pm 0.06$ & $8.8 \pm 4.1$ & $4.0 \pm 1.9$ & $4.8 \pm 1.8$ & $0.3 \pm 0.2$ \\
\hline & $0.6 / 2.2$ & $0.1 / 0.1$ & $1.3 / 5.6$ & $0.8 / 4.0$ & $1.1 / 4.0$ & $0.5 / 0.5$ \\
\hline \multirow[t]{2}{*}{ CK8/18 } & $4.1 \pm 0.6$ & $1.6 \pm 0.3$ & $8.1 \pm 3.3$ & $27.3 \pm 14.3$ & $136.3 \pm 10.7$ & $107.3 \pm 29.1$ \\
\hline & $1.0 / 4.1$ & $1.0 / 1.6$ & $1.2 / 5.8$ & $1.2 / 18.6$ & $2.1 / 64.0$ & $2.3 / 43.5$ \\
\hline \multirow[t]{2}{*}{ CK19 } & $2.4 \pm 1.2$ & neg. & $3.7 \pm 0.6$ & $9.6 \pm 5.1$ & $2.8 \pm 0.7$ & $65.3 \pm 19.9$ \\
\hline & $1.1 \pm 1.7$ & neg./neg. & $1.0 / 3.7$ & $1.2 / 6.5$ & $0.8 / 3.0$ & $1.7 / 35.3$ \\
\hline \multirow[t]{2}{*}{ CK20 } & neg. & $2.6 \pm 0.6$ & $4.6 \pm 2.8$ & $3.1 \pm 0.3$ & $2.3 \pm 0.7$ & $2.7 \pm 1.0$ \\
\hline & neg./neg. & $1.0 / 2.6$ & $1.1 / 3.1$ & $1.0 / 3.1$ & $0.8 / 2.5$ & $0.7 / 2.7$ \\
\hline \multirow[t]{2}{*}{ Vim } & $59.5 \pm 12.6$ & $58.2 \pm 5.9$ & $15.2 \pm 2.6$ & $27.7 \pm 11.8$ & $16.8 \pm 6.4$ & $4.8 \pm 2.0$ \\
\hline & $2.3 / 24.3$ & $2.0 / 29.1$ & $1.7 / 8.6$ & $1.5 / 15.8$ & $1.5 / 10.0$ & $1.1 / 3.7$ \\
\hline \multicolumn{7}{|c|}{ Progenitor markers } \\
\hline \multirow[t]{2}{*}{ C-kit } & $1.7 \pm 0.6$ & neg. & $2.3 \pm 1.0$ & $1.0 \pm 0.6$ & $0.8 \pm 0.5$ & $1.1 \pm 0.5$ \\
\hline & $0.8 / 1.8$ & neg./neg. & $0.7 / 2.5$ & $0.5 / 1.0$ & $0.5 / 1.0$ & $0.7 / 1.3$ \\
\hline \multirow[t]{2}{*}{ CD34 } & $1.8 \pm 1.4$ & $0.3 \pm 0.2$ & $3.1 \pm 0.4$ & $2.0 \pm 0.7$ & $0.9 \pm 0.2$ & $4.0 \pm 0.7$ \\
\hline & $0.7 / 1.1$ & $0.5 / 0.5$ & $1.0 / 3.1$ & $0.8 / 2.1$ & $0.8 / 1.0$ & $1.0 / 4.0$ \\
\hline \multirow[t]{2}{*}{ Thy-1 } & $4.7 \pm 1.0$ & $3.5 \pm 0.6$ & $18.7 \pm 3.1$ & $14.1 \pm 1.4$ & $45.1 \pm 13.7$ & $6.7 \pm 2.7$ \\
\hline & $1.0 / 4.7$ & $1.0 / 3.5$ & $1.2 / 14.7$ & $1.1 / 12.7$ & $2.1 / 20.0$ & $1.2 / 4.8$ \\
\hline \multicolumn{7}{|c|}{ Embryonic/ } \\
\hline \multicolumn{7}{|c|}{ Development markers } \\
\hline B-cat & $85.1 \pm 8.5$ & $23.7 \pm 2.7$ & $3.8 \pm 2.1$ & $105.9 \pm 39.2$ & $150.3 \pm 45.9$ & $13.1 \pm 1.9$ \\
\hline$m b^{c}$ & $1.7 / 49.0$ & $1.0 / 23.7$ & $0.7 / 4.1$ & $1.8 / 52.0$ & $1.8 / 75.2$ & $1.0 / 13.1$ \\
\hline B-cat & $7.2 \pm 3.0$ & $1.6 \pm 0.9$ & $9.8 \pm 2.8$ & $2.8 \pm 1.1$ & $3.1 \pm 1.0$ & $42.6 \pm 11.0$ \\
\hline $\mathrm{cp}^{\mathrm{c}}$ & $1.5 / 4.1$ & $0.5 / 1.6$ & $1.2 / 7.3$ & $0.7 / 2.8$ & $0.8 / 3.2$ & $1.5 / 27.2$ \\
\hline \multirow[t]{2}{*}{ PDX-1 } & $2.6 \pm 0.5$ & $2.0 \pm 0.6$ & $3.5 \pm 1.9$ & $1.5 \pm 0.2$ & $0.8 \pm 0.5$ & $13.5 \pm 3.5$ \\
\hline & $1.0 / 2.6$ & $0.8 / 2.1$ & $1.0 / 2.5$ & $1.0 / 1.5$ & $0.5 / 1.0$ & $1.7 / 7.1$ \\
\hline \multirow[t]{2}{*}{ SHH } & $0.1 \pm 0.1$ & $0.8 \pm 0.5$ & $0.06 \pm 0.06$ & $0.1 \pm 0.07$ & $0.06 \pm 0.06$ & $0.2 \pm 0.2$ \\
\hline & $0.1 / 0.2$ & $0.5 / 0.8$ & $0.1 / 0.1$ & $0.2 / 0.02$ & $0.1 / 0.1$ & $0.2 / 0.2$ \\
\hline \multirow[t]{2}{*}{ PTC } & $5.7 \pm 2.1$ & $11.0 \pm 1.9$ & $5.1 \pm 2.2$ & $1.2 \pm 0.4$ & $8.6 \pm 3.9$ & $0.2 \pm 0.2$ \\
\hline & $1.1 / 4.7$ & $1.2 / 9.0$ & $1.5 / 2.8$ & $0.7 / 1.2$ & $1.2 / 6.1$ & $0.2 / 0.2$ \\
\hline
\end{tabular}

${ }^{a}$ Score as well as intensity and extensity levels (mean \pm standard deviation). ${ }^{b}$ For Ki-67 only extensity levels were included. ${ }^{c}$ Expression of ß-catenin was differentially evaluated: mb, membranous and cp, cytoplasmatic. Neg, negative.

and factor analysis could extract major groups of differentiation within the analyzed hepatic cancer cell lines.

Overall, the investigated differentiation markers showed an association with the hepatic cancer cell lines: Huh7 and its derivatives were associated with a high expression of CK7 and vimentin but with a low expression of CK8/18. Hep3B and HepG2, in contrast, were mainly correlated with expression of
CK8/18 and CK19. CK8/18 is usually expressed in normal hepatocytes, while CK7/19 is additionally found in cholangiocytes and especially in hepatic progenitor cells $(20,21)$. The overall very low expression of CK20 suggests that gastro-intestinal glandular differentiation does not play an important role in $\mathrm{HCC}$ cell lines as was previously demonstrated for human $\operatorname{HCC}(22,23)$. In addition, the 



Figure 4. Typical expression pattern of trans- and dedifferentiation inside HCC tumor cell line implants in nude mice as determined by immunohistochemistry (magnification: HE-staining x200) (bar $50 \mu \mathrm{m}$ ), all others x400 objective (bar $20 \mu \mathrm{m}$ ). The expression of CK7, CK8/18, CK19, CK20 and vimentin were used as markers for intermediar filaments differentiation, expression of C-kit, CD34 and Thy-1 as markers for progenitor differentiation and finally 3 -catenin, PDX-1, SHH and PTC as markers for embryonic/development differentiation. Based on these protein expression levels the hierarchical cluster and factor analysis identified the following predominant differentiation: Group 1 (Huh-7, Huh-7 pcDNA3.1 and Hep3B): CK7, CK19, B-catenin and CD34 (classical CCC type); group 2 (Huh-7 5-15): CK19, vimentin, Ki-67 (dedifferentiated mesenchymal-proliferative type); group 3 (Hep3B-MG): CK19, B-catenin and PTC (dedifferentiated embryonic-development type); group 4 (HepG2): CK18, CK19, B-catenin (classical HCC type). 
Table VI. Correlation analysis giving significant associations between the applied biomarkers.

\begin{tabular}{|c|c|c|}
\hline & $\begin{array}{c}\text { Positive } \\
\text { (Correlation } \\
\text { coefficient/p) }\end{array}$ & $\begin{array}{l}\text { Negative } \\
\text { (Correlation } \\
\text { coefficient/p) }\end{array}$ \\
\hline Ki-67 & No correlation & $\operatorname{Vim}(-0.402 / 0.015)$ \\
\hline CK7 & CK20 (0.607/0.002) & \\
\hline CK8/18 & $\begin{array}{l}\text { CK19 (0.430/0.036) } \\
\text { Thy-1 (0.446/0.029) }\end{array}$ & $\operatorname{Vim}(-.475 / 0.019)$ \\
\hline CK19 & $\begin{array}{r}\text { CK19 }(0.430 / 0.036) \\
\text { B-cat cp }(0.803 / 0.000) \\
\text { PDX-1 }(0.802 / 0.000)\end{array}$ & PTC $(-0.395 / 0.05)$ \\
\hline CK20 & CK7 (0.607/0.002) & No correlation \\
\hline Vim & No correlation & $\begin{array}{r}\text { Ki-67 (-0.402/0.015) } \\
\text { CK8/18 (-.475/0.019) } \\
\text { CD34 (-0.493/0.014) } \\
\text { B-cat cp }(-0.409 / 0.047)\end{array}$ \\
\hline C-kit & & No correlation \\
\hline CD34 & $\begin{array}{l}\text { B-cat cp }(0.407 / 0.048) \\
\text { PDX-1 }(0.406 / 0.049)\end{array}$ & $\operatorname{Vim}(-0.493 / 0.014)$ \\
\hline Thy-1 & $\begin{array}{r}\text { Thy-1 }(0.446 / 0.029) \\
\text { B-cat mb }(0.462 / 0.023)\end{array}$ & relation \\
\hline B-Cat mb & Thy-1 (0.462/0.023) & No correlation \\
\hline B-Cat cp & $\begin{array}{r}\text { CK19 }(0.803 / 0.000) \\
\text { CD34 }(-0.409 / 0.047) \\
\text { PDX-1 }(0.557 / 0.005)\end{array}$ & $\operatorname{Vim}(-0.409 / 0.047)$ \\
\hline PDX-1 & $\begin{array}{r}\text { CK19 }(0.802 / 0.000) \\
\text { CD34 }(0.406 / 0.049) \\
\text { B-cat cp }(0.557 / 0.005)\end{array}$ & No correlation \\
\hline SHH & & No correlation \\
\hline PTC & No correlation & CK19 $(-0.395, \mathrm{p}=0.05)$ \\
\hline
\end{tabular}

$\mathrm{Mb}$, membranous and cp, cytoplasmatic.

negative to very low expression levels of progenitor factors such as c-kit (CD117), CD34 or Thy-1 (CD90) underline that stem cell plasticity is not a very prominent phenomenon in the used setting, although higher expression levels of CD34 and Thy-1 were observed in HepG2 and Hep3B-MG xenografts, associated with higher proliferation activity in these cases as evidenced using Ki-67 staining. Recently, Thy-1 has been shown to be decisive for tumorigenicity of HCC cell lines, and although the overall expression of this marker is usually $<1 \%$ (24) it was proposed as a novel marker for diagnosis and treatment of human HCC (25). Notably, expression of c-kit was linked to Hepatitis B virus infection, which is mirrored by the higher expression in Hep3B and Huh-7 in our setting, which were established on the basis of viral hepatitis $(26,27)$.
In our experiments, embryonic/developmental markers play a more prominent role than progenitor markers. Literature on WNT-pathway gives evidence that a more membranous expression of $\beta$-catenin is associated with better grading and outcome of HCC (28-31). Membranous $\beta$-catenin expression was mainly found in Huh-7, Hep3B and Hep3B-MG, whereas cytoplasmatic $\beta$-catenin was especially high in $\mathrm{HepG} 2$ cells, which was also associated with another embryonic marker PDX-1. This marker is relevant in embryonic development of the pancreas and plays a decisive role also in pancreatic carcinogenesis (16,32). PDX-1 also induces a developmental redirection of liver cells to the pancreatic lineage and has been suggested to be involved in transdifferentiation process of the liver (33-35). Recently, it was shown that PDX-1 influences hepatic differentiation processes via repression of the key hepatic transcription factor CCAAT/enhancer-binding protein $B(\mathrm{C} / \mathrm{EBPB})(36)$, which itself is a member of the family of the liver enriched transcription factors that have been shown to regulate differentiation processes in hepatocellular carcinoma (37).

The Hedgehog (Hh) pathway is essentially involved in gastrointestinal and liver development as well as stem cell maintenance (38). While normal hepatocytes do not express Hh proteins, this pathway is commonly activated in hepatic stellate cells (39), HCC cell lines (38) and specimens $(40,41)$ and biliary derived cells (42), usually accompanied by a high expression of the Hh receptor Patched (PTC) and its downstream transcription factors Gli. Consistent with this view, we found a high expression of the ligand SHH in all xenografts except HepG2 and Huh-7 5-15, whereas the receptor PTC showed high expression levels in Huh-7pcDNA3.1 and Hep3B-MG as demonstrated by immunohistochemistry.

Our comparison of the in vitro and the in vivo setting revealed differential expression patterns of the investigated markers and identifies the importance of matrix environment in tumor patterning. It is therefore interesting to note that under in vitro conditions, higher mRNA levels of the stem cell factors Thy-1 and c-kit were observed, while in vivo high levels of Shh were observed, indicating that differential pathways of growth control and regulation of differentiation can be reactivated dependent on the cellular environment. The tumor microenvironment is regarded as a key regulator of cellular survival, differentiation pathways and metastasis pathways $(43,44)$, e.g. by soluble factors such as TGF- $\beta(45)$ or by direct cell-cell or cell-matrix contacts (46). Dependent on the extracellular environment, a differential behaviour of tumor and stem cells has therefore been described (47). We are aware that our experimental approach using a subcutaneous xenograft model of HCC might not be representative when comparing our data with orthotopic models of liver cancer. Interestingly, the matrigel environment used for implantation of Hep3B cells to nude mice was already sufficient to influence the expression pattern of the investigated markers. Besides extracellular matrix, DNA methylation was another regulatory mechanism of selective gene activation showing heterogeneous methylation patterns between the used markers as well as the in vitro/in vivo situation. This is in line with recent investigations indicating the relevance of epigenetics in the tumorigenesis of hepatocellular carcinoma (48-50). Nevertheless, the relevance of these discrepant 
methylation patterns must be investigated in further functional experiments.

The correlation analysis revealed interesting associations in the xenograft model: the ductal differentiation marker CK7 is associated with the gastrointestinal-glandular marker, whereas the hepatic differentiation marker CK8/18 is associated with the known ductal marker CK19 (23). In the liver CK19 is known to be a marker of dedifferentiation (51), which showed a positive correlation with other embryonic/ development markers such as cytoplasmatic ß-catenin, PDX-1 and PTC. Surprisingly, the mesenchymal marker vimentin was negatively associated with the progenitor markers CD34 and cytoplasmatic B-catenin, which was generally not the case in other studies $(30,31)$. In line with the literature, and thereby indicating the association of progenitor potency and embryonic dedifferentiation, CD34 and Thy-1 were linked to the embryonic/developmental markers PDX-1 and B-catenin and vice versa (52-54).

In summary, our data show that different cell lines of human hepatocellular carcinoma have the capability to resort to different pathways of embryonic development or progenitor cell differentiation, dependent on the microenvironment. These findings highlight the importance of selecting appropriate experimental conditions, especially for investigating novel targeted therapies interfering with the growth factor or survival pathways that may be differentially expressed under varying experimental conditions.

\section{Acknowledgements}

We thank Gabriele Krumholz for support in animal care and experiments. The excellent technical assistance of Ursula Becker, Ines Grob-Achleitner, Astrid Taut and Isabel Zeitträger is gratefully acknowledged.

\section{References}

1. Thorgeirsson SS: Hepatic stem cells. Am J Pathol 142: 1331-1333, 1993.

2. Ponder KP: Analysis of liver development, regeneration, and carcinogenesis by genetic marking studies. FASEB J 10: 673-682, 1996.

3. Corcelle V, Stieger B, Gjinovci A, Wollheim CB and Gauthier BR: Characterization of two distinct liver progenitor cell subpopulations of hematopoietic and hepatic origins. Exp Cell Res 312: 2826-2836, 2006.

4. Wu XZ and Yu XH: Bone marrow cells: the source of hepatocellular carcinoma? Med Hypotheses 69: 36-42, 2007.

5. Thorgeirsson SS: Hepatic stem cells in liver regeneration. FASEB J 10: 1249-1256, 1996.

6. Sirica AE, Mathis GA, Sano N and Elmore LW: Isolation, culture, and transplantation of intrahepatic biliary epithelial cells and oval cells. Pathobiology 58: 44-64, 1990.

7. Aterman K: The stem cells of the liver - a selective review. J Cancer Res Clin Oncol 118: 87-115, 1992.

8. Fausto N, Lemire JM and Shiojiri N: Cell lineages in hepatic development and the identification of progenitor cells in normal and injured liver. Proc Soc Exp Biol Med 204: 237-241, 1993.

9. Sigal SH, Brill S, Fiorino AS and Reid LM: The liver as a stem cell and lineage system. Am J Physiol 263: G139-G148, 1992.

10. Sell S: Liver stem cells. Mod Pathol 7: 105-112, 1994.

11. Grisham JW: A morphologic study of deoxyribonucleic acid synthesis and cell proliferation in regenerating rat liver; autoradiography with thymidine-H3. Cancer Res 22: 842-849, 1962.
12. Sell S: Cellular origin of cancer: dedifferentiation or stem cell maturation arrest? Environ Health Perspect 101 (Suppl 5): 15-26, 1993.

13. Grisham JW: Migration of hepatocytes along hepatic plates and stem cell-fed hepatocyte lineages. Am J Pathol 144: 849-854, 1994.

14. Zajicek G, Oren R and Weinreb M Jr: The streaming liver. Liver 5: 293-300, 1985.

15. Neureiter D, Herold C and Ocker M: Gastrointestinal cancer - only a deregulation of stem cell differentiation? (Review). Int J Mol Med 17: 483-489, 2006

16. Neureiter D, Zopf S, Dimmler A, et al: Different capabilities of morphological pattern formation and its association with the expression of differentiation markers in a xenograft model of human pancreatic cancer cell lines. Pancreatology 5: 387-397, 2005.

17. Quint K, Stintzing S, Alinger B, et al: The expression pattern of pdx-1, shh, patched and gli-1 is associated with pathological and clinical features in human pancreatic cancer. Pancreatology 9: 116-126, 2009.

18. Lohmann V, Korner F, Koch J, Herian U, Theilmann L and Bartenschlager R: Replication of subgenomic hepatitis $\mathrm{C}$ virus RNAs in a hepatoma cell line. Science 285: 110-113, 1999.

19. Pietschmann T, Lohmann V, Rutter G, Kurpanek K and Bartenschlager R: Characterization of cell lines carrying selfreplicating hepatitis C virus RNAs. J Virol 75: 1252-1264, 2001.

20. Lai YS, Thung SN, Gerber MA, Chen ML and Schaffner F: Expression of cytokeratins in normal and diseased livers and in primary liver carcinomas. Arch Pathol Lab Med 113: 134-138, 1989.

21. Roskams T, De Vos R, Van Eyken P, Myazaki H, Van Damme B and Desmet V: Hepatic OV-6 expression in human liver disease and rat experiments: evidence for hepatic progenitor cells in man. J Hepatol 29: 455-463, 1998.

22. Chu P, Wu E and Weiss LM: Cytokeratin 7 and cytokeratin 20 expression in epithelial neoplasms: a survey of 435 cases. Mod Pathol 13: 962-972, 2000.

23. Yamamoto T, Uenishi T, Ogawa M, et al: Immunohistologic attempt to find carcinogenesis from hepatic progenitor cell in hepatocellular carcinoma. Dig Surg 22: 364-370, 2005.

24. Yang ZF, Ho DW, Ng MN, et al: Significance of CD90 ${ }^{+}$cancer stem cells in human liver cancer. Cancer Cell 13: 153-166, 2008.

25. Yang ZF, Ngai P, Ho DW, et al: Identification of local and circulating cancer stem cells in human liver cancer. Hepatology 47: 919-928, 2008.

26. Lee ES, Han EM, Kim YS, et al: Occurrence of c-kit ${ }^{+}$tumor cells in hepatitis B virus-associated hepatocellular carcinoma. Am J Clin Pathol 124: 31-36, 2005.

27. Chung CY, Yeh KT, Hsu NC, et al: Expression of c-kit protooncogene in human hepatocellular carcinoma. Cancer Lett 217: 231-236, 2005.

28. Inagawa $\mathrm{S}$, Itabashi $\mathrm{M}$, Adachi $\mathrm{S}$, et al: Expression and prognostic roles of beta-catenin in hepatocellular carcinoma: correlation with tumor progression and postoperative survival. Clin Cancer Res 8: 450-456, 2002.

29. Hsu HC, Jeng YM, Mao TL, Chu JS, Lai PL and Peng SY: Beta-catenin mutations are associated with a subset of low-stage hepatocellular carcinoma negative for hepatitis B virus and with favorable prognosis. Am J Pathol 157: 763-770, 2000.

30. Tien LT, Ito M, Nakao M, et al: Expression of beta-catenin in hepatocellular carcinoma. World J Gastroenterol 11: 2398-2401, 2005.

31. Suzuki T, Yano H, Nakashima Y, Nakashima O and Kojiro M: Beta-catenin expression in hepatocellular carcinoma: a possible participation of beta-catenin in the dedifferentiation process. J Gastroenterol Hepatol 17: 994-1000, 2002.

32. Neureiter D, Zopf S, Leu T, et al: Apoptosis, proliferation and differentiation patterns are influenced by Zebularine and SAHA in pancreatic cancer models. Scand J Gastroenterol 42: 103-116, 2007.

33. Sapir T, Shternhall K, Meivar-Levy I, et al: Cell-replacement therapy for diabetes: Generating functional insulin-producing tissue from adult human liver cells. Proc Natl Acad Sci USA 102: 7964-7969, 2005.

34. Li WC, Horb ME, Tosh D and Slack JM: In vitro transdifferentiation of hepatoma cells into functional pancreatic cells. Mech Dev 122: 835-847, 2005.

35. Horb ME, Shen CN, Tosh D and Slack JM: Experimental conversion of liver to pancreas. Curr Biol 13: 105-115, 2003. 
36. Meivar-Levy I, Sapir T, Gefen-Halevi S, et al: Pancreatic and duodenal homeobox gene 1 induces hepatic dedifferentiation by suppressing the expression of CCAAT/enhancer-binding protein beta. Hepatology 46: 898-905, 2007.

37. Hayashi Y, Wang W, Ninomiya T, Nagano H, Ohta K and Itoh H: Liver enriched transcription factors and differentiation of hepatocellular carcinoma. Mol Pathol 52: 19-24, 1999.

38. Sicklick JK, Li YX, Jayaraman A, et al: Dysregulation of the Hedgehog pathway in human hepatocarcinogenesis. Carcinogenesis 27: 748-757, 2006.

39. Sicklick JK, Li YX, Choi SS, et al: Role for hedgehog signaling in hepatic stellate cell activation and viability. Lab Invest 85: 1368-1380, 2005.

40. Huang S, He J, Zhang X, et al: Activation of the hedgehog pathway in human hepatocellular carcinomas. Carcinogenesis 27: 1334-1340, 2006.

41. Patil MA, Zhang J, Ho C, Cheung ST, Fan ST and Chen X: Hedgehog signaling in human hepatocellular carcinoma. Cancer Biol Ther 5: 111-117, 2006.

42. Omenetti A, Porrello A, Jung Y, et al: Hedgehog signaling regulates epithelial-mesenchymal transition during biliary fibrosis in rodents and humans. J Clin Invest 118: 3331-3342, 2008.

43. Le NH, Franken P and Fodde R: Tumour-stroma interactions in colorectal cancer: converging on beta-catenin activation and cancer stemness. Br J Cancer 98: 1886-1893, 2008.

44. Witz IP: Tumor-microenvironment interactions: dangerous liaisons. Adv Cancer Res 100: 203-229, 2008.
45. Massague J: TGFbeta in Cancer. Cell 134: 215-230, 2008.

46. Schuppan D and Ocker M: Integrin-mediated control of cell growth. Hepatology 38: 289-291, 2003.

47. Marongiu F, Doratiotto S, Montisci S, Pani P and Laconi E: Liver repopulation and carcinogenesis: two sides of the same coin? Am J Pathol 172: 857-864, 2008.

48. Tischoff I and Tannapfe A: DNA methylation in hepatocellular carcinoma. World J Gastroenterol 14: 1741-1748, 2008.

49. Herath NI, Leggett BA and MacDonald GA: Review of genetic and epigenetic alterations in hepatocarcinogenesis. J Gastroenterol Hepatol 21: 15-21, 2006.

50. De Zhu J: The altered DNA methylation pattern and its implications in liver cancer. Cell Res 15: 272-280, 2005.

51. Durnez A, Verslype C, Nevens F, et al: The clinicopathological and prognostic relevance of cytokeratin 7 and 19 expression in hepatocellular carcinoma. A possible progenitor cell origin. Histopathology 49: 138-151, 2006.

52. Gao X, Song L, Shen K, Wang H, Niu W and Qin X: Transplantation of bone marrow derived cells promotes pancreatic islet repair in diabetic mice. Biochem Biophys Res Commun 371: 132-137, 2008.

53. Li H, Li X, Lam KS, Tam S, Xiao W and Xu R: Adeno-associated virus-mediated pancreatic and duodenal homeobox gene-1 expression enhanced differentiation of hepatic oval stem cells to insulin-producing cells in diabetic rats. J Biomed Sci 15: 487-497, 2008.

54. Loo CK and Wu XJ: Origin of stellate cells from submesothelial cells in a developing human liver. Liver Int (In press). 